

\title{
Another law of small numbers: Patterns of trading prices in experimental markets*
}

\author{
Tristan Roger ${ }^{\dagger} \quad$ Wael Bousselmi ${ }^{\ddagger} \quad$ Patrick Roger ${ }^{\S} \quad$ Marc Willinger ${ }^{\natural}$
}

October 25, 2018

\begin{abstract}
Conventional finance models indicate that the magnitude of stock prices should not influence portfolio choices or future returns. This view is contradicted, however, by empirical evidence. In this paper, we report the results of an experiment showing that trading prices, in experimental markets, are processed differently by participants, depending on their magnitude. Our experiment has two consecutive treatments. One where the fundamental value is a small number (the small price market) and a second one where the fundamental value is a large number (the large price market). Small price markets exhibit greater mispricing than large price markets. We obtain this result both between-participants and within-participants. Our findings show that price magnitude influences the way people perceive the distribution of future returns. This result is at odds with standard finance theory but is consistent with: (1) a number of observations in the empirical finance and accounting literature; and (2) evidence in neuropsychology on the use of different mental scales for small and large numbers.
\end{abstract}

Keywords: Experimental markets, number perception, behavioral bias, stock price magnitude, mental scales

*We thank Sébastien Duchêne, Nicolas Eber, Carol Osler and Hélène Rainelli-Weiss for their comments, as well as seminar participants at EM Strasbourg Business School, LaRGE Research Center, and participants of the Experimental Finance 2017 Conference, the 15th Affi-Eurofidai International Paris Finance Meeting, the 8th ASFEE Conference and the 35th International Conference of the French Finance Association. Patrick Roger acknowledges the financial support of the Chair in Behavioral Finance at EM Strasbourg Business School. Marc Willinger acknowledges the financial support of the BEAM project - Behavioral and Experimental Analyses in Macro-finance - (ANR-15-ORAR-0004-02). This paper has received the ASFEE 2017 Best Paper Prize.

${ }^{\dagger}$ DRM Finance, Université Paris-Dauphine, PSL Research University - Mailing address: Place du Maréchal de Lattre de Tassigny, 75775 Paris Cedex 16 FRANCE - Tel: +33 (0) 144054490 - Email: tristan.roger@dauphine.fr

${ }^{\ddagger}$ CREST, ENSAE, École Polytechnique Université Paris-Saclay - Mailing address: 5 Avenue Henry Le Châtelier, 91120 Palaiseau, France - Email: wael.bousselmi@ensae.fr

${ }^{\S}$ LaRGE Research Center, EM Strasbourg Business School, University of Strasbourg - Mailing address: 61 avenue de la Forêt Noire, 67085 Strasbourg Cedex FRANCE - Tel: +33 (0) 368852156 - Email: proger@unistra.fr

ףUniversité de Montpellier, CEE-M, UFR d'Economie - Mailing address: Avenue Raymond Dugrand, CS 79606, 34960 Montpellier Cedex 2, France - Email: marc.willinger@umontpellier.fr 


\section{Introduction}

Normative decision theory assumes that expectations are not sensitive to changes in the way information is presented. For instance, the magnitude of a stock price should not influence portfolio choices, return expectations or future realized returns. Empirical evidence on financial markets, however, indicates that stock price levels have an impact on stock returns, analysts' forecasts and investors' portfolio choices. For instance, Schultz (2000) finds that: (1) retail investors hold lower-priced stocks than institutions; and, (2) the number of retail investors among shareholders of a firm, increases after a forward stock split that decreases the stock price without changing the fundamentals of the firm. Green and Hwang (2009) show that the returns on small (large) price stocks comove more together, than with the returns on large (small) price stocks. Birru and Wang (2016) argue that investors overestimate the skewness of returns of small price stocks. Baker et al. (2009) find that firms manage nominal prices through forward stock splits when investors are willing to pay a premium for small price stocks. More recently, Roger et al. (2018) show that price forecasts issued by financial analysts deviate more from realized prices for small price stocks, compared to those of large price stocks.

Yet, the question of why the magnitude of stock prices matters is still unanswered. ${ }^{1}$ In this paper, we propose a novel explanation for the influence of stock price magnitude on agents' behavior. We posit that economic agents process small and large prices differently, as a result of a differential processing of small and large numbers by the human brain. The literature in neuropsychology devoted to the spatial representation of numbers, indicates that humans process numbers on a logarithmic scale (Dehaene, 2003); that is, the perception of numbers obeys Weber's law (also called Weber-Fechner law). ${ }^{2}$ Weber's law describes the relationship between the physical magnitude of a stimulus and its perceived intensity. It states that the ability to detect a change in a stimulus is proportional to the magnitude of this stimulus. In his original work, Weber (1850) found that while a person is able to discriminate between two weights of $20 \mathrm{~g}$ and $21 \mathrm{~g}$, it is necessary to add $2 \mathrm{~g}$ to a weight of $40 \mathrm{~g}$ in order to notice the difference in weight. This notion of Just Noticeable Difference (JND), that is, the minimum change for a stimulus to be noticeable, has been found for many stimuli such as: sight, sound, taste, touch and for the perception of numbers.

\footnotetext{
${ }^{1}$ The proposed explanations are either based on stock characteristics (lottery features of small price stocks) or on investors' mistakes in estimating the skewness of future returns.

${ }^{2} \mathrm{~A}$ complete review on the mental representation of numbers can be found in Dehaene (2011).
} 
The logarithmic scale implies that large numbers are perceived as being closer together compared to reality, that is, large numbers are compressed on the mental scale. With the acquisition of formal (mathematical) education, a shift from a logarithmic to a linear representation of numbers occurs (Siegler and Opfer, 2003; Laski and Siegler, 2007). However, the linear mapping does not entirely replace the logarithmic one: the two mental scales coexist. Dehaene et al. (2008) and Viarouge et al. (2010) show that the brain tends to process small numbers on a linear scale, while tending to apply the logarithmic scale for large numbers. ${ }^{3}$

Using an economic experiment, we investigate whether individuals behave differently when trading small price stocks compared to large price stocks. Our experiment involves eight sessions with two treatments each. One where the fundamental value of the traded asset is a small number (in experimental currency units) and one where the fundamental value is a large number. We refer to the former (latter) treatment as the small (large) price market. We test whether there are significant differences in mispricing across treatments. If both small prices and large prices were processed on a logarithmic scale, the minimum difference in prices to induce a perception of price change (i.e., the JND) would be proportionally smaller for small price markets than for large price markets. However, as a result of the use of a linear scale for small numbers, the minimum change in prices necessary to be perceived will be greater in small price markets, compared to what should be observed under Weber's law. Hence, we expect to observe greater mispricing when an individual trades in small price markets.

The experiment is based on a continuous double auction market (Smith et al. (1988), SSW hereafter) with a random fundamental value (FV hereafter) which is a martingale. The use of such a stochastic process for the FV (Gillette et al., 1999; Stöckl et al., 2015; Kirchler, 2009), without intermediate dividend payments, allows us to keep the magnitude of prices stable over time, a key issue for our research question. In addition, this type of FV process share more features with real financial markets (Stöckl et al., 2015). In the small (large) price market, the unconditional expected fundamental value is 6 (72).

\footnotetext{
${ }^{3}$ Banks and Coleman (1981) is one of the first papers referring to several mental scales for numbers. In particular, a logarithmic (linear) scale is used when numbers are sampled in an open (closed)-ended range. They conclude by saying, "Why do we carry two scales around with us? One justification could be found in the fact that sometimes we need to be aware of percentage differences and sometimes we need to be aware of amount of difference. An easy way to approximate percentage differences is to measure with a compressive scale, whereas a linear scale is needed to record amount differences. It is possible that the two subjective scales developed in response to these two different cognitive needs.".
} 
Overall, we find that these two different price regimes generate different magnitudes of mispricing. Consistent with the linear vs. logarithmic scales in processing numbers, we find greater mispricing in small price markets compared to large price markets. At the aggregate level (all markets pooled together), we find the average deviation from the fundamental value is more than 20 percentage points larger in small price markets than in large price markets. This result is obtained both between-participants and withinparticipants.

Our findings have important implications for experimental asset markets. Our results suggest that the conversion rate from experimental currency (or conversely, the magnitude of the FV) has an impact on potential mispricing in contrast to other experiments where the conversion rate of experimental currency does not seem to affect behavior (Drichoutis et al., 2015).

The remainder of the paper is organized as follows. Section 2 reviews previous literature on the small price effect and number processing. In section 3 , we describe our experimental design. Section 4 presents our results and section 5 concludes.

\section{Related literature}

\subsection{Small price effect in financial markets}

While deemed irrelevant by standard finance theory, the role of nominal prices in the determination of future returns is a long-standing debate in finance. The debate may be traced back to Fritzemeier (1936) who showed that small price stocks fluctuate more than large price stocks. He also found an asymmetry in price reactions of small price stocks. Small price stocks rose more than large price stocks in bullish markets but the magnitude of the decrease was smaller in bearish markets. The study was performed over the years 1926-1934, thus including the period of the great depression. Fifteen years later, Clendenin (1951) challenged Fritzemeier's result and argued that the result was an artifact. When controlling for the quality of stocks (measured by the Fitch rating at that time), the small price effect disappeared. In other words, differences in returns were justified by differences in risk, a result which is in line with finance theory in the fifties. Pinches and Simon (1972) used a more sophisticated approach to test the relationship between price 
level and future returns. They compared a buy-and-hold strategy to a fixed proportion or reallocation strategy with penny stocks (initially priced less than $5 \$$ ). They show that the two strategies generate significantly different results, therefore showing a small price effect.

The more recent literature confirms the existence of this peculiarity of small price stocks. Green and Hwang (2009) demonstrate that small (large) price stocks comove more together, than with large (small) price stocks, a result confirmed by Kumar et al. (2016). The interpretation provided by Green and Hwang (2009) is that investors think that low price stocks have "more room to grow" than large price stocks. Kumar et al. (2016) have a slightly different interpretation, which is linked to the propensity of retail investors to gamble. The two interpretations refer more or less explicitly to the preference of retail investors for positive skewness. Kumar et al. (2016) use the LIDX index (Kumar, 2009) which combines the three characteristics of a lottery-like stock: a low price, a high variance of return and a high positive skewness. The second feature (high variance) is a by-product of the third one (high skewness) because what is attractive in lottery tickets is the existence of a large and unlikely jackpot. So positive skewness is the crucial point, not the high variance induced by the existence of the jackpot. As a consequence, a start-up stock is attractive because of the unlikely possibility that the firm could be the next Google or Amazon. Several papers show that investors with a taste for gambling trade more in lottery-like stocks and influence prices (Kumar et al., 2011; Dorn and Sengmueller, 2009; Grinblatt and Keloharju, 2001). Birru and Wang (2016), in a paper titled "Nominal price illusion", conclude that small price stocks are overpriced because investors overestimate the positive skewness of their returns.

\section{$2.2 \quad$ Number processing}

The ability of humans to process numbers is deeply rooted and precedes the acquisition of mathematical language and culture. The human brain is endowed with an innate mechanism to process quantities (which we share with many species). Animals, human babies and human adults all possess an intuitive number sense (often referred to as the Approximate Number Sense (ANS)). ${ }^{4}$ This non-symbolic representation of numbers takes the form

\footnotetext{
${ }^{4}$ See Gallistel and Gelman (1992); Pepperberg (2006); Agrillo et al. (2008, 2009); Nieder and Dehaene (2009); Garland et al. (2012); Perdue et al. (2012); Mehlis et al. (2015) for studies on animals and Xu and Spelke (2000); Lipton and Spelke (2003); Xu et al. (2005); Izard et al. (2009); Libertus and Brannon (2009, 2010); Hyde and Spelke (2011) for studies on babies.
} 
of a mental number line and follows Weber's law. Weber's law is a psychological law that quantifies the perception of change in a given stimulus. This law states that for a change in stimulus to be noticed, the magnitude of the change must be proportional to the magnitude of the original stimulus. Weber's law implies two behavioral responses. First, when ranking quantities, the reaction time and the error rate is a decreasing function of the difference between the two numbers. It is faster to distinguish two distant numerosities ${ }^{5}$, such as 60 and 80 than two closer numbers such as 61 and 62 (Moyer and Landauer, 1967). This is called the distance effect. Second, when the distance between two numbers remains the same, it is easier and quicker to compare two small numbers than two larger numbers. For instance, it is easier to discriminate 25 dots from 20 dots than to discriminate 75 dots from 70 dots. This is called the size (or magnitude) effect. It follows that numerosities are processed by the human brain on a logarithmic scale (Nieder, 2005). The use of symbolic number representations, i.e., Arabic numerals and number words, distinguishes human adults from animals and babies. Starting with an intuitive number sense, children progressively acquire formal mathematical education (Siegler and Opfer, 2003; Laski and Siegler, 2007). As the result of a better understanding of numbers, the logarithmic scale progressively gives way to a linear mapping of numbers onto the mental number line. However, while the use of a symbolic representation of numbers helps to better discriminate between different quantities, research in neuroscience suggests that the processing of numbers is deeply rooted in the ANS. ${ }^{6}$ As a result, the linear scale and the logarithmic scale have been found to coexist (Dehaene et al., 2008; Lourenco and Longo, 2009; Viarouge et al., 2010; Núñez et al., 2011; Anobile et al., 2012; Dotan and Dehaene, 2013), small numbers being processed on a linear scale and large numbers on a logarithmic scale.

\footnotetext{
${ }^{5}$ The word "numerosity" is generally used in this literature to refer to non-symbolic representations (dots for instance)

${ }^{6}$ Recently, there has been increased interest in the link between the ANS and the performance in symbolic mathematics. Several studies report a positive correlation between ANS precision and mathematical abilities both for infants (Halberda and Feigenson, 2008; Mundy and Gilmore, 2009; Gilmore et al., 2010; Libertus et al., 2011; Mazzocco et al., 2011; Libertus et al., 2013; Starr et al., 2013; van Marle et al., 2014; Pinheiro-Chagas et al., 2014; Geary et al., 2015; Keller and Libertus, 2015; Chu et al., 2015; Soto-Calvo et al., 2015) and adults (DeWind and Brannon, 2012; Agrillo et al., 2013; Halberda et al., 2012; Libertus et al., 2012; Lourenco et al., 2012).
} 


\section{Experimental design}

\subsection{Experimental implementation}

The experiment was conducted at the LEEM, the computerized laboratory of the University of Montpellier, with the software z-Tree (Fischbacher, 2007). We ran eight sessions involving a total of 72 participants, randomly selected from a subject pool containing over 5,000 volunteers from the University of Montpellier. ${ }^{7}$ No participant took part in more than one session.

At first, participants earned money by completing a real effort task (in order to mitigate the house money effect). They were informed that they would not be allowed to participate in the subsequent parts of the experiment if they were unable to successfully complete the real effort task (in which case they would be compensated with the show up fee). After completion of this preliminary task, participants were awarded 30 Euros. The Euros were then converted, for the second part of the experiment, into units of asset and experimental currency. ${ }^{8}$ The real effort task lasted 15 minutes and consisted of a series of counting exercises. Here, participants had to count the number of "ones" contained in a sequence of matrices of various sizes whose cells contained either 0 or 1.

At the beginning of the second part of the experiment, participants were briefed using written instructions which were followed by one trial period. Each participant was assigned to a group of nine traders. ${ }^{9}$ The subjects were only informed that they would participate in two consecutive markets. They were not told about the specifics of the second market until the end of the first market.

\footnotetext{
${ }^{7}$ We selected only students who are comfortable in mathematics (undergraduate third year students of Mathematics, Medicine, Physics, Biology and the School of Engineering, and Master's Degree students in Economics, Computer Science and Pharmacology) in order to prevent our results from being caused simply by participants' difficulties in manipulating numbers.

${ }^{8}$ All participants successfully completed the real effort task.

${ }^{9}$ Other participants were assigned to a different role (analyst) where they could only observe the market data without being able to intervene. Results from the analysts are available in a companion paper. Traders did not see analysts' forecasts and did not communicate with analysts.
} 


\subsection{Market architecture}

In a given session, traders participated in two consecutive continuous double auction markets. Each market consisted of ten periods of 120 seconds each. Traders could place as many buy and sell orders as they wanted provided they held enough units of experimental currency to buy or enough units of assets to sell. The experimental currency used in the experiment was called ECU. The appendix provides an excerpt of the user-guide explaining how to submit a buy or a sell order and how to realize a transaction. Short-selling and borrowing were not allowed. Within a given market, holdings of experimental currency and assets were carried over from one period to the next. The order book was visible to all traders at any time. Realized transactions were displayed on each trader's screen as and when they were executed. After each period, the software computed the current value of each trader's portfolio as follows: Current value of portfolio = available ECUs + (units of asset $\times$ closing price), where the closing price is the last transaction price of the asset in the current period (screenshots and instructions can be found in the appendix).

\subsection{Traded asset}

The traded asset has a finite life of ten periods. After each period of trading, a number is randomly drawn from a uniform distribution with five outcomes and displayed to all participants, as the current cash-flow. The set of potential cash-flows is $\{0.0,0.3,0.6,0.9,1.2\}$ in the small price treatment, and $\{0.0,3.6,7.2,10.8,14.4\}$ in the large price treatment. The traded asset does not pay any dividend but is repurchased by the experimenter at its redemption value at the end of the market. The instructions made it clear that the redemption value would be equal to the sum of the ten cash-flows. The cash-flows, while randomly drawn from a uniform distribution, are pre-determined. Panel A of Table 1 provides the four different sequences of cash-flows. Note that sequences S3 and S4 are "mirrored" versions of sequences S1 and S2 (with respect to the unconditional fundamental value). Stöckl et al. (2015) underline that the general trend of the FV process may influence mispricing. Gillette et al. (1999) and Kirchler (2009) show that markets with predominantly decreasing (increasing) FV tend to exhibit overvaluation (undervaluation). We follow Stöckl et al. (2015) in using sequences S1 and S2 in the four first sessions and their mirrored counterparts S3 and S4 in the following four sessions.

Since we opted for a within-participant design, each session involved two consecutive 
treatments: a small price treatment and a large price treatment. Half of the sessions started with the small price treatment and the other half with the large price treatment. In the large price treatment, the expected fundamental value of the asset is scaled up by 12 compared to the small price treatment. ${ }^{10}$

\subsection{Endowments}

At the beginning of each market, traders were endowed with heterogeneous portfolios consisting of several units of asset and some amount of experimental currency (ECU). There were three different types of portfolios. A portfolio of a given type was allocated to three participants. The existence of different portfolio types was common knowledge. As a result, participants were able to calculate the total number of outstanding units of the risky asset (i.e., 54). However, participants did not know the exact allocation of portfolios. Details about portfolio composition and cash-flow processes are provided in Table 1. We ensured that participants did not get the same endowments in the two markets in order for them to fully understand that the asset traded in the second market was different from the asset traded in the first market. In large price markets, the FV is 12 times the one in small price markets. The balance between the total value of cash at the start and the total asset value has an impact on subsequent asset prices (Caginalp et al., 1998, 2001). To avoid this effect, we multiply the available units of experimental currency by 12 in the large price market in order to keep the cash/asset ratio constant.

\subsection{Earnings}

Participants were informed that only one of the two consecutive markets would be randomly selected at the end to be paid out in real currency. Experimental currency accumulated during this market (including the redemption value of the asset) was converted into Euros to calculate the earnings for the session. The payment rule is:

Payment $($ in Euros $)=\frac{\text { Individual portfolio terminal value (in ECUs) }}{\text { Sum of the } 9 \text { individual portfolio terminal values (in ECUs) }} \times 270$

\footnotetext{
${ }^{10}$ The purpose of choosing a scaling factor of 12 (visible in the cash-flow vectors), an integer that is not a round number, is to prevent participants from perceiving immediately that the second market is simply a scaled version of the first market.
} 
The total endowment of the group of nine traders $(30 \times 9)$ was reallocated according to the relative performance of each trader. Note that this method is incentive compatible if participants try to maximize the value of their portfolio and is independent of the magnitude of asset prices. The exchange rate thus depended on the type of market that was randomly selected. If the small price market was selected, the exchange rate was 3.33 ECUs for 1 Euro. It was 40 ECUs for 1 Euro if the large price market was selected.

Available experimental evidence suggests that the exchange rate from experimental currency to real currency has mixed effects. Experiments about altruistic (Mazar et al., 2008; Reinstein and Riener, 2012) behavior found a tendency to behave more altruistically and to cheat more when decision outcomes are labeled as experimental currency units. These findings suggest that the use of artificial currencies tends to discount the moral cost of deviating from pro-social behavior. However available evidence about bidding behavior in second-price auctions (Drichoutis et al., 2015) does not reveal any difference in mispricing between real and experimental, suggesting that the conversion rate effects are specific to experiments involving actions with a moral dimension. Nevertheless, more evidence about the effects of conversion rates between experimental and real currencies seems warranted.

\section{Results}

\subsection{Univariate analysis}

Figure 1 reports the evolution of individual market prices (gray lines with circles and squares) and of the FVs (bold line). In sessions 1,3,5 and 7 (respectively 2, 4, 6 and 8), the first market is a small (large) price market. In the eight sessions shown in Figure 1, mean prices tend to be higher than the fundamental values in most periods. Mean prices appear to deviate more from the FV in small price markets than in large price markets. A specific pattern in prices appears at the beginning of the second markets. When the second market is a large price market, mean prices are much lower than the FV in the first couple of periods. On the contrary, when the second market is a small price market, mean prices of the first periods greatly exceed the FV. In all but one session, traders underreact to the change of the cash-flow regime. Traders appear to anchor on the last period prices of the first market. It takes about two periods for some traders to fully assimilate the change of 
the cash-flow regime. ${ }^{11}$ This feature is consistent with the results of Duclos (2015) who finds that the last closing price has a disproportionate influence on investment behavior, a phenomenon he calls end-anchoring.

We follow Stöckl et al. (2010) in measuring the magnitude of the deviations of prices from the FV by calculating the Relative Absolute Deviation (RAD) and the Relative Deviation (RD). ${ }^{12}$ Table 2 reports averages for $\mathrm{RAD}$ and $\mathrm{RD}$ for small and large price markets. Figure 2 displays the empirical cumulative distribution function (ECDF) for these two measures and provides p-values from Mann-Whitney $U$ tests for difference in averages between small price markets and large price markets.

The results in Table 2 indicate that small price markets exhibit greater mispricing (mainly greater overpricing) than large price markets. When all markets are pooled together (i.e., at the aggregate level), RAD is higher in small price markets (32.58\%) than in large price markets (18.75\%). Similar results are obtained for RD. RD is $20.90 \%$ for small price markets compared to $-1.44 \%$ in large price markets. The empirical distributions in Figure 2 confirm that traders deviate more from the FV in small price markets. For both $\mathrm{RAD}$ and RD, the ECDF of large price markets (solid black line) is systematically on the left of the ECDF of small price markets (gray dashed line). Reported Mann-Whitney U tests, indicate that the differences in RAD and RD between small price markets and large price markets are significant. The study of first markets and second markets separately, yields the same conclusion: small price markets exhibit less efficient pricing than large price markets. However, the difference in RAD (and RD) is greater for second markets. This increased difference is particularly striking for RD and can be explained by traders' underreaction to the change of cash-flow regime. Indeed, when the second market is a

\footnotetext{
${ }^{11}$ We ensured that participants understood that the asset traded in a second market was a different asset from the one in the first market. Specifically, the instructions given at the beginning of the second market clearly indicated that while the mechanism of the second market was identical to the one of the first market, the cash-flows and the initial portfolios were different. As a result, it is more likely that what we observe at the beginning of the second market is caused by anchoring rather than by money illusion (Fehr and Tyran, 2001, 2007; Noussair et al., 2012). In addition, during experiments on money illusion, the underreaction following the nominal shock is long-lasting and asymmetric while, in our experiment, we have a symmetric and short-lived reaction.

${ }^{12}$ For transaction $i$ in market $m$ in period $p$, RAD and RD are defined as

$$
R A D_{i, p}^{m}=\frac{\left|P_{i, p}^{m}-F V_{p}^{m}\right|}{\overline{F V}} \text { and } R D_{i, p}^{m}=\frac{P_{i, p}^{m}-F V_{p}^{m}}{\overline{F V}^{m}} .
$$

where $P_{i, p}^{m}$ is the price of transaction $i$ in market $m$ in period $p, F V_{p}^{m}$ is the fundamental value in period $p$ of market $m$ and $\overline{F V}^{m}$ is the average fundamental value for market $m$.
} 
large price market, traders' anchor on the first market's prices (that is, small prices). We, thus, observe a negative deviation of prices from the FV. On the contrary, when the second market is a small price market, the first transactions occur at large prices, generating positive deviations. While the mispricing in second markets may be explained in part by underreaction, our results on first markets do not suffer from the same issue and provide an ideal setup for a between-participants analysis.

While the underreaction, which takes place at the beginning of the second market, is of concern to us, we want to take advantage of our within-participant design. Indeed, in our experiment, each of the 72 traders was involved in two markets, a small price market and a large price market. Thus, for each trader, the paired observations for RAD and RD allow us to test whether there are significant differences between the two markets. The within-participant design allows us to neutralize individual differences in deviations from the FV. Table 3 reports the results of our paired difference test. A Wilcoxon signed-rank test indicates that both RAD and RD are significantly larger (at a 1\% significance level) for small price markets compared to large price markets. The difference is about $18 \%$ for RAD and $27 \%$ for RD. We consider the influence of the initial underreaction in second markets and test whether our results are robust when excluding the first period and the two first periods of each market. The difference in RAD and RD between small price markets and large price markets decreases but remains large and significant. Thus, the observed difference in RAD and RD between small price and large price markets, is not a by-product of an underreaction to the change in the cash-flow process.

\subsection{Multivariate analysis}

To investigate further the small price bias, we conduct a multivariate analysis. Table 4 reports the results of regressions of RAD (Panel A) and RD (Panel B) on our treatment dummy (i.e., a small price dummy) and different control variables. In all specifications, we include our treatment dummy, a dummy variable that is equal to one if the transaction takes place during the second market and 0 otherwise, the period number, the transaction number within a period, and a dummy for the cash-flow sequence type (a value of 0 corresponds to sequence S1 followed by sequence $\mathrm{S} 2$ - in the first four sessions - and a value of 1 corresponds to S3 followed by S4 - in the next four sessions). In specification (1), we consider all transactions. Specification (2) is the same specification as (1) but we cluster standard errors at the order initiator level. In specification (3), we cluster standard 
errors at the session level. In specification (4), we remove trades that took place in the first period to account for the initial underreaction in second markets. Finally, specification (5) considers only transactions that take place in first markets.

Our treatment dummy, the small price dummy, is positive and strongly significant at the $1 \%$ significance level in all specifications. The $t$-stat is larger than 10 in the baseline specification for RAD and greater than 4 for RD. In fact, for RAD (RD), the regression coefficient of the small price dummy is 0.2952 (0.1042) with a corresponding standard error of $0.021(0.027)$. Across specifications, the minimum value of the regression coefficient is 0.1921 for RAD and 0.0600 for RD when only first markets are considered. Overall, the regression results indicate that traders exhibit greater overvaluation in small price markets than in large price markets.

\section{Conclusion}

This paper investigates the impact of price magnitude on trading prices observed on experimental markets. We show the existence of a small price effect. Prices deviate more from fundamental values in small price markets compared to large price markets. On a small (large) price market with an unconditional fundamental value of 6 (72), RD is $20.90 \%$ $(-1.44 \%)$. This result is in line with recent empirical literature in finance and accounting, showing that market participants behave differently when trading small price and large price assets. Our within participant design allows us to argue that the main reason for the difference between markets is the co-existence of two mental scales, a linear one for small numbers and a logarithmic one for large numbers. We are able to measure betweenparticipants and within-participants effects of price magnitude. In the within-participants analysis, we find that the average participant trades in small price markets at an average deviation from the fundamental value, which is approximately 27 percentage points larger than the corresponding deviation in the large price market. The result is striking since the two types of markets are identical, except that we scaled up the FV and cash holdings by a factor of 12 .

Our results make significant contributions in different domains. First, we show that the price magnitude is not a neutral choice in experimental studies; bubbles are larger in small price markets, a result that has not been shown before. Our findings underline a potential impact of the conversion rate from experimental currency to real currency. 
Second, our paper contributes to the finance literature since the controlled environment of our experiments puts into perspective the traditional explanations for the small price effect, such as the lottery features of small price stocks or investors' mistakes in estimating the skewness of future returns. Finally, our paper also contributes to the literature on the perception of numbers. To the best of our knowledge, the literature in neuropsychology does not consider numbers in the context of financial markets. Our paper shows that the peculiarity of small numbers can also be found in an economic environment.

\section{References}

Agrillo, C., Dadda, M., Serena, G., Bisazza, A., 2008. Do fish count? Spontaneous discrimination of quantity in female mosquitofish. Animal Cognition 11, 495-503.

Agrillo, C., Dadda, M., Serena, G., Bisazza, A., 2009. Use of Number by Fish. PLoS ONE $4, \mathrm{e} 4786$.

Agrillo, C., Piffer, L., Adriano, A., 2013. Individual differences in non-symbolic numerical abilities predict mathematical achievements but contradict ATOM. Behavioral and Brain Functions pp. 9-26.

Anobile, G., Cicchini, G. M., Burr, D. C., 2012. Linear mapping of numbers onto space requires attention. Cognition 122, 454-459.

Baker, M., Greenwood, R., Wurgler, J., 2009. Catering through nominal share prices. Journal of Finance 64, 2559-2590.

Banks, W. P., Coleman, M. J., 1981. Two subjective scales of number. Perception and Psychophysics 29, 95-105.

Birru, J., Wang, B., 2016. Nominal price illusion. Journal of Financial Economics 119, $578-598$.

Caginalp, G., Porter, D. P., Smith, V. L., 1998. Initial cash/asset ratio and asset prices: An experimental study. Proceedings of the National Academy of Sciences 95, 756-761.

Caginalp, G., Porter, D. P., Smith, V. L., 2001. Financial bubbles: excess cash, momentum, and incomplete information. Journal of Psychology and Financial Markets 2, 80-99. 
Chu, F. W., VanMarle, K., Geary, D. C., 2015. Early numerical foundations of young children's mathematical development. Journal of Experimental Child Psychology 132, 205-212.

Clendenin, J. C., 1951. Quality versus price as factors influencing common stock price fluctuations. Journal of Finance 6, 398-405.

Dehaene, S., 2003. The neural basis of the Weber-Fechner law: a logarithmic mental number line. Trends in Cognitive Sciences 7, 145-147.

Dehaene, S., 2011. The number sense: How the mind creates mathematics. Oxford University Press.

Dehaene, S., Izard, V., Spelke, E., Pica, P., 2008. Log or linear? Distinct intuitions of the number scale in Western and Amazonian indigene cultures. Science 320, 1217-1220.

DeWind, N. K., Brannon, E. M., 2012. Malleability of the approximate number system: effects of feedback and training. Frontiers in Human Neuroscience 6, 68.

Dorn, D., Sengmueller, P., 2009. Trading as entertainment. Management Science 55, 591603.

Dotan, D., Dehaene, S., 2013. How do we convert a number into a finger trajectory? Cognition 129, 512-529.

Drichoutis, A. C., Lusk, J. L., Nayga, R., 2015. The veil of experimental currency units in second price auctions. Journal of the Economic Science Association 1, 182-196.

Duclos, R., 2015. The psychology of investment behavior: (De)biasing financial decisionmaking one graph at a time. Journal of Consumer Psychology 25, 317-325.

Fehr, E., Tyran, J.-R., 2001. Does Money Illusion Matter? The American Economic Review 91, 1239-1262.

Fehr, E., Tyran, J. R., 2007. Money illusion and coordination failure. Games and Economic Behavior 58, 246-268.

Fischbacher, U., 2007. z-tree: Zurich toolbox for ready-made economic experiments. Experimental Economics 10, 171-178.

Fritzemeier, L. H., 1936. Relative price fluctuations of industrial stocks in different price groups. Journal of Business 2, 133-154. 
Gallistel, C. R., Gelman, R., 1992. Preverbal and verbal counting and computation. Cognition 44, 43-74.

Garland, A., Low, J., Burns, K. C., 2012. Large quantity discrimination by North Island robins (Petroica longipes). Animal Cognition 15, 1129-1140.

Geary, D. C., Hoard, M. K., Nugent, L., Rouder, J. N., 2015. Individual differences in algebraic cognition: Relation to the approximate number and semantic memory systems. Journal of Experimental Child Psychology 140, 211-227.

Gillette, A. B., Stevens, D. E., Watts, S. G., Williams, A. W., 1999. Price and volume reactions to public information releases: An experimental approach incorporating traders' subjective beliefs. Contemporary Accounting Research 16, 437-479.

Gilmore, C. K., McCarthy, S. E., Spelke, E. S., 2010. Non-symbolic arithmetic abilities and mathematics achievement in the first year of formal schooling. Cognition 115, 394-406.

Green, C. T., Hwang, B.-H., 2009. Price-based return comovement. Journal of Financial Economics 93, 37-50.

Grinblatt, M., Keloharju, M., 2001. Sensation seeking, overconfidence, and trading activity. Journal of Finance 64, 549-578.

Halberda, J., Feigenson, L., 2008. Developmental change in the acuity of the "number sense": The approximate number system in 3-, 4-, 5-, and 6-year-olds and adults. Developmental Psychology 44, 1457-1465.

Halberda, J., Ly, R., Wilmer, J. B., Naiman, D. Q., Germine, L., 2012. Number sense across the lifespan as revealed by a massive Internet-based sample. Proceedings of the National Academy of Sciences 109, 11116-11120.

Hyde, D. C., Spelke, E. S., 2011. Neural signatures of number processing in human infants: evidence for two core systems underlying numerical cognition. Developmental Science $14,360-371$.

Izard, V., Sann, C., Spelke, E. S., Streri, A., 2009. Newborn infants perceive abstract numbers. Proceedings of the National Academy of Sciences 106, 10382-10385.

Keller, L., Libertus, M., 2015. Inhibitory control may not explain the link between approximation and math abilities in kindergarteners from middle class families. Frontiers in Psychology 6, 685. 
Kirchler, M., 2009. Underreaction to fundamental information and asymmetry in mispricing between bullish and bearish markets: An experimental study. Journal of Economic Dynamics and Control 33, 491-506.

Kumar, A., 2009. Who gambles in the stock market. Journal of Finance 64, 1889-1933.

Kumar, A., Page, J. K., Spalt, O., 2011. Religious beliefs, gambling attitudes, and financial market outcomes. Journal of Financial Economics 102, 671-708.

Kumar, A., Page, J. K., Spalt, O., 2016. Gambling and comovement. Journal of Financial and Quantitative Analysis 51, 85-111.

Laski, E. V., Siegler, R. S., 2007. Is 27 a big number? Correlational and causal connections among numerical categorization, number line estimation, and numerical magnitude comparison. Child Development 78, 1723-1743.

Libertus, M. E., Brannon, E. M., 2009. Behavioral and neural basis of number sense in infancy. Current Directions in Psychological Science 18, 346-351.

Libertus, M. E., Brannon, E. M., 2010. Stable individual differences in number discrimination in infancy. Developmental Science 13, 900-906.

Libertus, M. E., Feigenson, L., Halberda, J., 2011. Preschool acuity of the approximate number system correlates with school math ability. Developmental Science 14, 12921300.

Libertus, M. E., Feigenson, L., Halberda, J., 2013. Numerical approximation abilities correlate with and predict informal but not formal mathematics abilities. Journal of Experimental Child Psychology 116, 829-838.

Libertus, M. E., Odic, D., Halberda, J., 2012. Intuitive sense of number correlates with math scores on college-entrance examination. Acta Psychologica 141, 373-379.

Lipton, J. S., Spelke, E. S., 2003. Origins of number sense. Psychological Science 14, 396-401.

Lourenco, S. F., Bonny, J. W., Fernandez, E. P., Rao, S., 2012. Nonsymbolic number and cumulative area representations contribute shared and unique variance to symbolic math competence. Proceedings of the National Academy of Sciences 109, 18737-42. 
Lourenco, S. F., Longo, M. R., 2009. Multiple spatial representations of number : evidence for co-existing compressive and linear scales. Experimental Brain Research 193, 151-156.

Mazar, N., Amir, O., Ariely, D., 2008. The dishonesty of honest people: A theory of self-concept maintenance. Journal of Marketing Research 45, 633-644.

Mazzocco, M. M. M., Feigenson, L., Halberda, J., 2011. Preschoolers' precision of the approximate number system predicts later school mathematics performance. PLoS ONE 6, e23749.

Mehlis, M., Thünken, T., Bakker, T. C. M., Frommen, J. G., 2015. Quantification acuity in spontaneous shoaling decisions of three-spined sticklebacks. Animal Cognition 18, $1125-1131$.

Moyer, R. S., Landauer, T. K., 1967. Time required for Judgements of Numerical Inequality. Nature 215, 1519-1520.

Mundy, E., Gilmore, C. K., 2009. Children's mapping between symbolic and nonsymbolic representations of number. Journal of Experimental Child Psychology 103, 490-502.

Nieder, A., 2005. Counting on neurons: The neurobiology of numerical competence. Nature Reviews 6, 177-190.

Nieder, A., Dehaene, S., 2009. Representation of number in the brain. Annual Review of Neuroscience 32, 185-208.

Noussair, C. N., Richter, G., Tyran, J.-R., 2012. Money illusion and nominal inertia in experimental asset markets. Journal of Behavioral Finance 13, 27-37.

Núñez, R., Doan, D., Nikoulina, A., 2011. Squeezing, striking, and vocalizing: Is number representation fundamentally spatial? Cognition 120, 225-235.

Pepperberg, I. M., 2006. Grey parrot numerical competence: a review. Animal Cognition 9, 377-391.

Perdue, B. M., Talbot, C. F., Stone, A. M., Beran, M. J., 2012. Putting the elephant back in the herd: elephant relative quantity judgments match those of other species. Animal Cognition 15, 955-961.

Pinches, G. E., Simon, G. M., 1972. An analysis of portfolio accumulation strategies employing low-priced common stocks. Journal of Financial and Quantitative Analysis 7, 1773-1796. 
Pinheiro-Chagas, P., Wood, G., Knops, A., Krinzinger, H., Lonnemann, J., Starling-Alves, I., Willmes, K., Haase, V. G., 2014. In how many ways is the approximate number system associated with exact calculation? PLOS ONE 9, e111155.

Reinstein, D., Riener, G., 2012. Decomposing desert and tangibility effects in a charitable giving experiment. Experimental Economics 15, 229-240.

Roger, T., Roger, P., Schatt, A., 2018. Behavioral bias in number processing: Evidence from analysts' expectations. Journal of Economic Behavior \& Organization 149, 315331.

Schultz, P., 2000. Stock splits, tick size, and sponsorship. Journal of Finance 55, 429-450.

Siegler, R. S., Opfer, J. E., 2003. The development of numerical estimation: Evidence for multiple representations of numerical quantity. Psychological Science 14, 237-243.

Smith, V., Suchanek, G., Williams, A., 1988. Bubbles, crashes, and endogenous expectations in experimental spot asset markets. Econometrica 56, 1119-1151.

Soto-Calvo, E., Simmons, F. R., Willis, C., Adams, A.-M., 2015. Identifying the cognitive predictors of early counting and calculation skills: Evidence from a longitudinal study. Journal of Experimental Child Psychology 140, 16-37.

Starr, A., Libertus, M. E., Brannon, E. M., 2013. Number sense in infancy predicts mathematical abilities in childhood. Proceedings of the National Academy of Sciences 110, 18116-18120.

Stöckl, T., Huber, J., Kirchler, M., 2010. Bubble measures in experimental asset markets. Experimental Economics 13, 284-298.

Stöckl, T., Huber, J., Kirchler, M., 2015. Multi-period experimental asset markets with distinct fundamental value regimes. Experimental Economics 18, 314-334.

van Marle, K., Chu, F. W., Li, Y., Geary, D. C., 2014. Acuity of the approximate number system and preschoolers' quantitative development. Developmental Science 17, 492-505.

Viarouge, A., Hubbard, E., Dehaene, S., Sackur, J., 2010. Number line compression and the illusory perception of random numbers. Experimental Psychology 57, 446-454.

Weber, E. H., 1850. Der Tastsinn und das Gemeingefühl. In: R. Wagner (Ed.) (ed.), Hanwöter-buch der Physiologie, vol. 3, pp. 481-588. 
Xu, F., Spelke, E. S., 2000. Large number discrimination in 6-month-old infants. Cognition $74, \mathrm{~B} 1-\mathrm{B} 11$.

Xu, F., Spelke, E. S., Goddard, S., 2005. Number sense in human infants. Developmental Science 8, 88-101. 


\section{Appendix - Instructions to participants (translated from French) $)^{13}$}

\section{Sequence 1}

At this stage, you own the 30 Euros that you won in part 1. During part 2, you will use your 30 Euros to participate in experimental markets, in which you can make gains or losses. If you make gains they will be added to your 30 Euros and if you make losses, they will be deducted from your 30 Euros. Details about the calculation of your final gains (losses) are provided at the end of the instructions.

You will participate in two consecutive experimental markets in which you will be able to make transactions by buying and selling assets. All transactions are realized in Ecus. After reading the instructions, you will be invited to answer a brief questionnaire in order to assess your understanding of the tasks. Then, you will participate in a practice round to be trained with the transaction software. Eventual gains or losses during the practice round will not be counted in your final balance.

After the practice round...

\section{Generalities}

There are nine participants in the session.

1. Duration of a market and random draws

You will be involved in two consecutive markets. Each market consists of a sequence of 10 periods. Each period lasts two minutes during which you are able to make transactions. At the end of the session, only one of the two markets will be randomly selected to be paid in Euros. Your score for this market will be converted into Euros according to a conversion rule that will be given at the end of the instructions. The computer program will post your final score for the selected market.

The remainder of these instructions applies only to market 1 . Once market 1 is closed you will receive new instructions, specific to market 2.

\footnotetext{
${ }^{13}$ These instructions correspond to a session starting by a small price market
} 


\section{Portfolios}

Before the market opens, each trader receives a portfolio containing a number of units of asset and an amount of Ecus. A total of 54 units of asset can be traded in the market.

There are three types of portfolios, noted P1, P2 and P3. They differ by the number of units of asset and the amount of Ecus. A portfolio that contains more units of asset contains less Ecus, and vice versa, a portfolio that contains more Ecus contains less units of asset. The division of these portfolios among the traders is the following: three traders will get $\mathrm{P} 1$, three other traders $\mathrm{P} 2$ and the remaining three get $\mathrm{P}$. The assignment of a portfolio to a trader is made on a random basis. Each trader will be the only one to know exactly his portfolio.

3. Lifetime of assets and redemption value

In each period, traders can buy and sell units of asset. Each unit has a lifetime of 10 periods. After each period, the computer program selects randomly the cash-flow (in Ecu) attached to each unit of asset (see below the determination of cash-flows). At the end of the 10 periods, the market closes. All units of asset held by a trader are bought back by the experimenter at the same unit price for all traders, called the redemption value. The redemption value is equal to the sum of the 10 cash-flows randomly drawn during the market.

4. Cash-flows

Five cash-flow values (in Ecus) can occur, $\{0 ; 0.3 ; 0.6 ; 0.9 ; 1.2\}$. At the end of each period, the computer randomly selects the value of the cash-flow for the period. Each of the five possible values is equally likely, i.e. one chance out of five. The selected cash-flow is posted on participants' screens and is identical for all units of asset. The computer screen also displays the sum of the cash-flows revealed since the beginning of the market. Note that the selected cash-flow in any given period is not distributed to the asset owners. Therefore, it does not affect the amount of Ecus available in the traders' portfolios. Cash-flows are only used to determine the redemption value of each unit of asset at the end of period 10. As mentioned before, this redemption value is equal to the sum of all cash-flows revealed over the 10 periods.

Example 1 Consider the following sequence of cash-flows:

The redemption value of each unit of asset is equal to the sum of the cash-flows over the 10 periods: $0.3+0.0+0.9+0.9+\ldots+1.2+0.6=6.0$ Ecus. In this example, 


\begin{tabular}{lrrrrrrrrrr}
\hline Period & 1 & 2 & 3 & 4 & 5 & 6 & 7 & 8 & 9 & 10 \\
Cash-flow & 0.3 & 0.0 & 0.9 & 0.9 & 0.6 & 0.3 & 0.3 & 0.9 & 1.2 & 0.6 \\
Cumulated cash-flow & 0.3 & 0.3 & 1.2 & 2.1 & 2.7 & 3.0 & 3.3 & 4.2 & 5.4 & 6.0 \\
\hline
\end{tabular}

each unit of asset would be bought back by the experimenter at a price of 6 ecus at the end of period 10.

5. Carrying over portfolios

The portfolio of each trader is carried over from one period to the next without changing its content.

Example 2

At the end of period 5, a trader's portfolio contains 5 units of asset and 67 Ecus. At the beginning of period 6 the composition of his portfolio will be identical: 5 units of asset and 67 Ecus.

6. Losses and profits

The value of a portfolio can change from one period to the next, even if its composition is unchanged because the value of a portfolio depends on the price of the asset.

Example 3

At the end of period 7, your portfolio contains 80 Ecus and 3 units of asset. The last traded price was 7.2 Ecus. At the beginning of period 8, the value of each unit of asset is equal to 7.2 Ecus and the value of your portfolio is equal to $80+(3 \times 7.2)$ $=101.6$ Ecus. At the end of period 8, the asset price is equal to 7.6 Ecus. If you did not trade during period 8 , the value of your portfolio is equal to $80+(3 \times 7.6)=$ 102.8 Ecus, that is an increase of 1.2 Ecus corresponding to $3 \times(7,6-7,2)=1.2$ Ecus.

Example 4

At the end of period 7 , your portfolio contains 80 Ecus and 3 units of asset. The last traded price was 7.2 Ecus. At the beginning of period 8, the value of each unit of asset is equal to 7.2 Ecus and the value of your portfolio is equal to $80+(3 \times 7.2)$ $=101.6$ Ecus. At the end of period 8, the asset price is equal to 5.7 Ecus. If you did not trade during period 8 , the value of your portfolio is equal to $80+(3 \times 5.7)$ 
$=97.1$ Ecus, that is a decrease of 4.5 Ecus corresponding to $3 \times(5.7-7.2)=-4.5$ Ecus.

7. Conditions for transactions

In any given period, a trader cannot sell more units than he owns in his portfolio. Equivalently, a trader cannot buy a unit of asset if he does not own the corresponding amount of Ecus.

8. Earnings

At the end of the experiment, one of the two markets (market 1 or market 2) will be randomly selected for the payment, in Euros, of all traders. The conversion rule from ECUs to Euros in the selected market is detailed below.

\section{Conversion rule}

The total payment for the nine traders is $30 \times 9=270 €$ (this corresponds to the total amount obtained by all the traders at the end of part 1 of the experiment). Your gain depends on the return of your own portfolio during the 10 periods and on the returns of other traders' portfolios. Specifically, your gain in Euros is calculated as follows:

Payment in $€=270 \times \frac{\text { Terminal value of your portfolio }}{\text { Sum of the terminal values of the portfolios of the } 9 \text { traders }}$

\section{Sequence 2}

The instructions below are specific to market 2. The group of traders remain the same as in market 1 and the functioning of market 2 is identical to market 1, with two exceptions:

- new portfolios will be assigned to traders

- cash-flow values are different

Changes are detailed below.

\section{Generalities}

1. Portfolios 
As for market 1, the total number of available units of asset in market 2 is equal to 54. In market 2 , new starting portfolios will be assigned to the traders, noted $\mathrm{P} 4$, $\mathrm{P} 5$ and $\mathrm{P} 6$. As in market 1, 3 traders will receive $\mathrm{P} 4,3$ other traders will receive $\mathrm{P} 5$ and the 3 remaining traders will receive portfolio $\mathrm{P} 6$. The assignment will be made on a random basis. Each trader will be the only one to know exactly his portfolio.

2. Cash-flows

In market 2, five cash-flow values can occur : $\{0,3.6,7.2,10.8,14.4\}$. Each of the five possible values is equally likely, i.e. each one has one chance out of five to be drawn. At the end of each period, the selected cash-flow will be posted on all participants' screens, as well as the sum of the realized cash-flows since the beginning of the market. The selected cash-flow in any given period is not distributed to asset owners and, therefore, does not affect the amount of Ecus available to a trader. The cash-flows are only used to determine the redemption value of each unit of asset at the end of period 10. This redemption value is equal to the sum of all cash-flows revealed over the 10 periods.

Example 1

The sequence of cash-flows for market 2 is as follows:

\begin{tabular}{lrrrrrrrrrr}
\hline Period & 1 & 2 & 3 & 4 & 5 & 6 & 7 & 8 & 9 & 10 \\
Cash-flow & 3.6 & 0 & 10.8 & 10.8 & 7.2 & 3.6 & 3.6 & 10.8 & 14.4 & 7.2 \\
Cumulated cash-flow & 3.6 & 3.6 & 14.4 & 25.2 & 32.4 & 36 & 39.6 & 50.4 & 64.8 & 72 \\
\hline
\end{tabular}

The redemption value in this example is equal to: $3.6+0+10.8+10.8+\ldots+14.4+7.2=$ 72 Ecus. Each unit of asset held by a trader at the end of the 10 periods is bought back by the experimenter at a price of 72 Ecus.

3. Rules of market 2

The rules of market 2 are identical to those of market 1 . As for market 1, market 2 is divided into 10 periods. Each period lasts 2 minutes. Traders will therefore have 20 minutes for realizing their transactions. Remember that at the end of part 2, one of the two markets (market 1 or market 2) will be randomly selected to be paid for real. The computer will calculate your earnings for the selected market. 


\section{User-guide for the software}

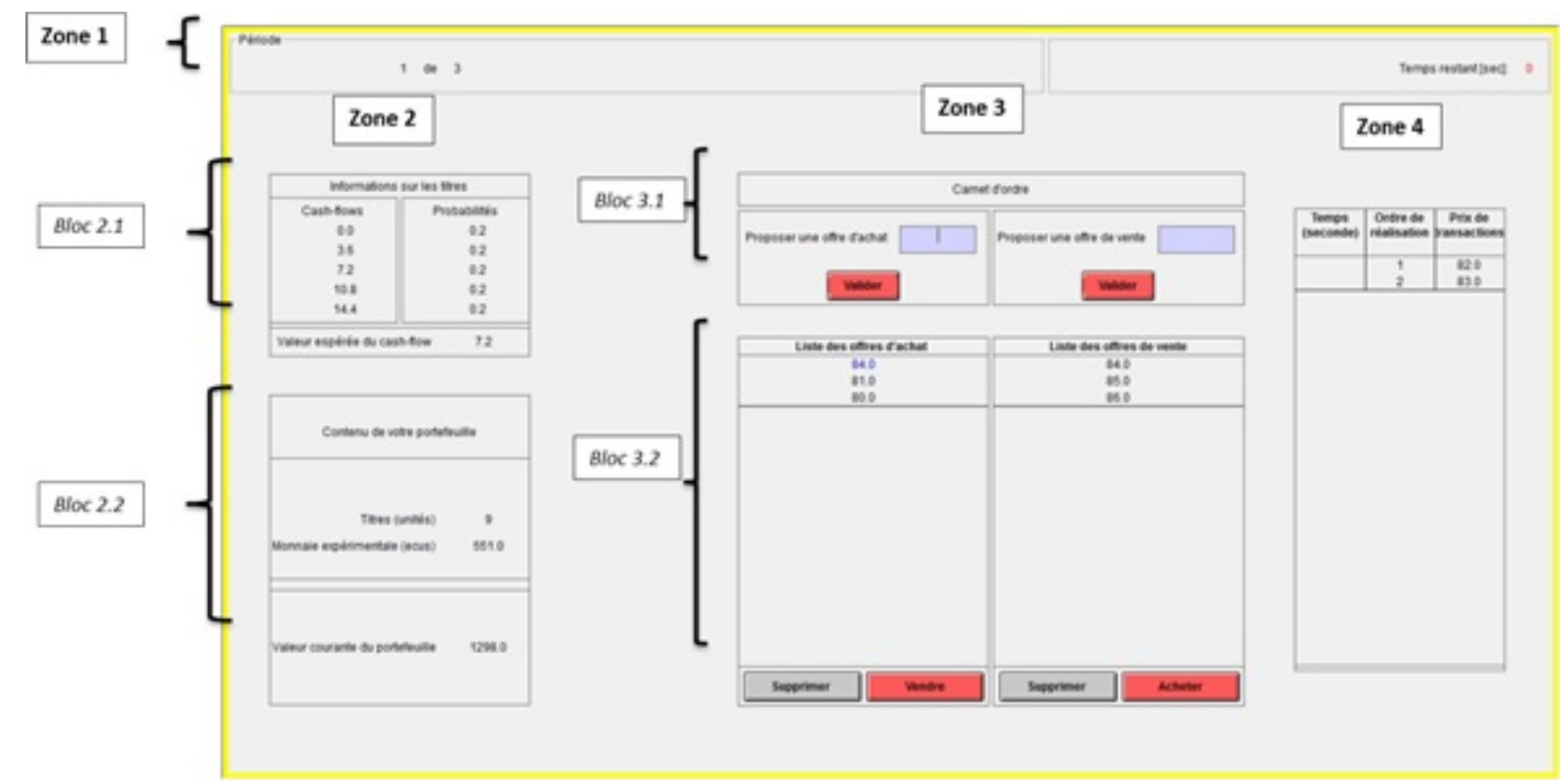

\section{Transaction screen}

In each period a screen similar to the one above will be displayed on your computer. Different information appears on this screen. For ease of description, information is grouped into 4 areas. Zone 3 is the main zone, it will allow you to follow the evolution of transactions and traders to make purchases or sales. Block 3.1 allows traders to make purchase and sale offers. Block 3.2 contains the order book. This is the display area for all offers to buy and sell. Each trader will be able to easily identify his own sales and purchase offers: they will appear in blue color while the other offers will be displayed in black. Note that the contents of the order book are visible to all.

\section{Issuing bids and asks}

Each trader can submit an ask (sale offer) for a unit of asset that he wishes to sell or a bid (purchase offer) for a unit of asset that he wishes to acquire. The bids and asks are displayed in the order book. The order book has two columns: a column which contains the list of bids (left column) and a column which contains the list of asks (right column). In each period the lists are updated as new offers are made and transactions are made. This is illustrated in the example below. (several examples (not reported) illustrate how the order book is updated (1) following new incoming bids , (2) following new incoming asks, (3) following the acceptance of a bid and (4) following the acceptance of an ask). 


\section{Zone 1}

On the left hand side the number of the current period is displayed. The right hand side shows the remaining time (in seconds) in the current period.

\section{Zone 2}

Zone 2 has two blocks: Block 2.1 entitled "Information on securities", reminds you of the possible values for the cash flows of the period, and the corresponding probabilities. Note that the information of this block is common to all members of the group. Block 2.2 entitled "Contents of your portfolio" is specific to each trader and visible only to him. It shows to each trader the composition of his portfolio for the current period: the number of units of asset, the amount of cash and the current value of his portfolio in Ecus (during the experiment this value starts to be displayed at the end of period 1).

\section{Zone 3}

Zone 3 on your screen corresponds to the transaction area. Block 3.1 allows traders to make bids and asks Block 3.2 corresponds to the order book. This is the display area of all bids and asks. Each trader will be able to easily identify his own bids and asks: they will appear in blue color while the other offers will be displayed in black. Note that the contents of the order book are visible to all (traders and analysts).

Important notes: The bids are ranked in descending order: the highest bid will always be at the top of the list. This is the bid that is most likely to be accepted by another trader. Selling offers are ranked in ascending order: the lowest offer will always be at the top of the list. This is the bid that is most likely to be accepted by another trader.

\section{Zone 4}

As transactions are made during the period, the price of each transaction is displayed in the order of execution in the "Realized Prices" panel. The time in seconds is displayed in the column "Time (seconds)" and the order of completion is displayed in the "Order of completion" column. Note that the Zone 4 chart is visible by all members of the group. 
This screen appears at the end of each period (for 15 seconds).

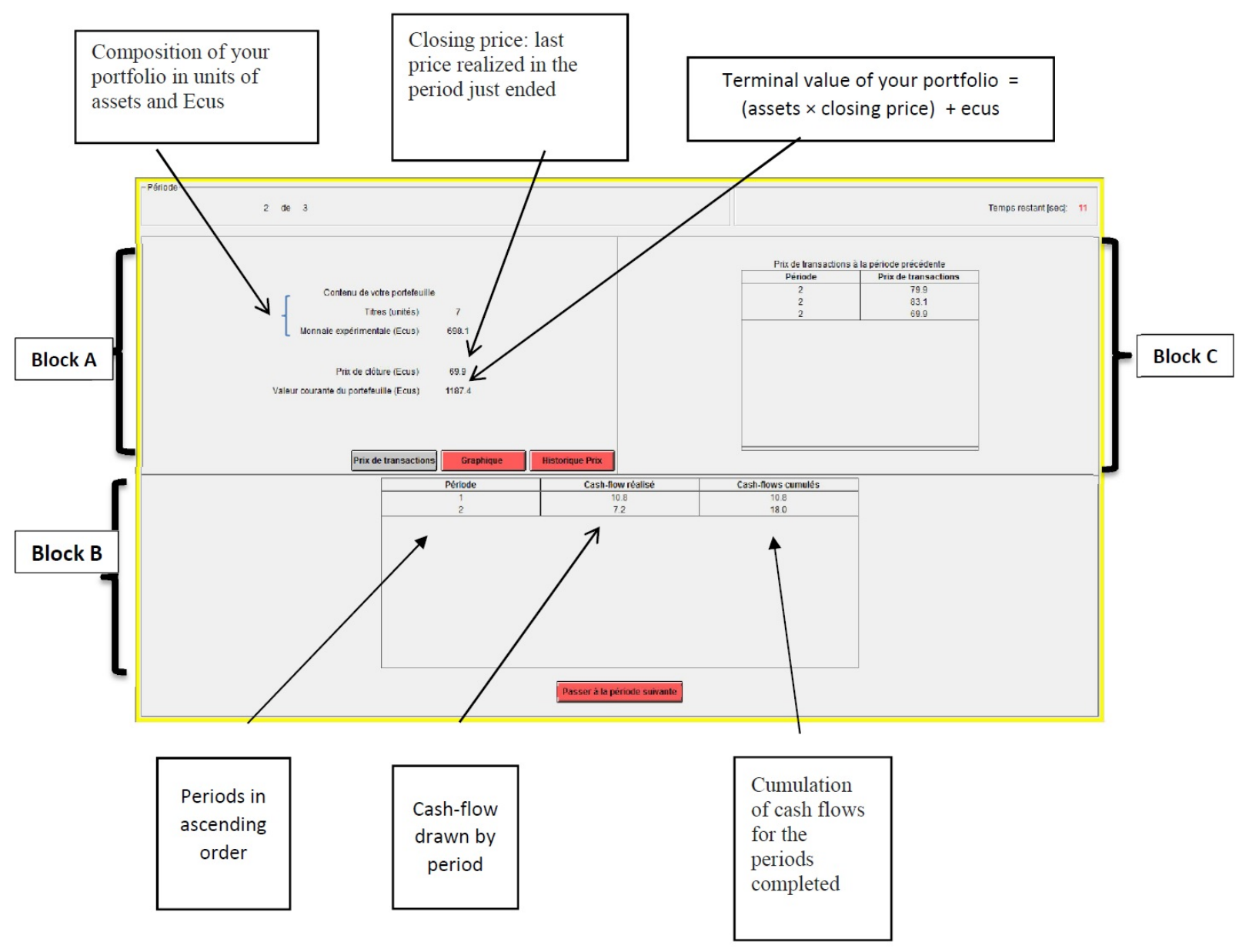

Block $\mathrm{C}$ represents a display area of 3 types of information:

1- The price history achieved in the period just ended (display 1)

2- The evolution of the closing price during the past periods (display 2)

3- All the price history since the beginning of the market (display 3)

(N.B. a screenshot for each type of information was provided in the instructions) 
Figure 1

Fundamental value (bold line) and mean prices for individual markets (gray lines with circles and squares). The $\mathrm{x}$-axis represents the different periods.
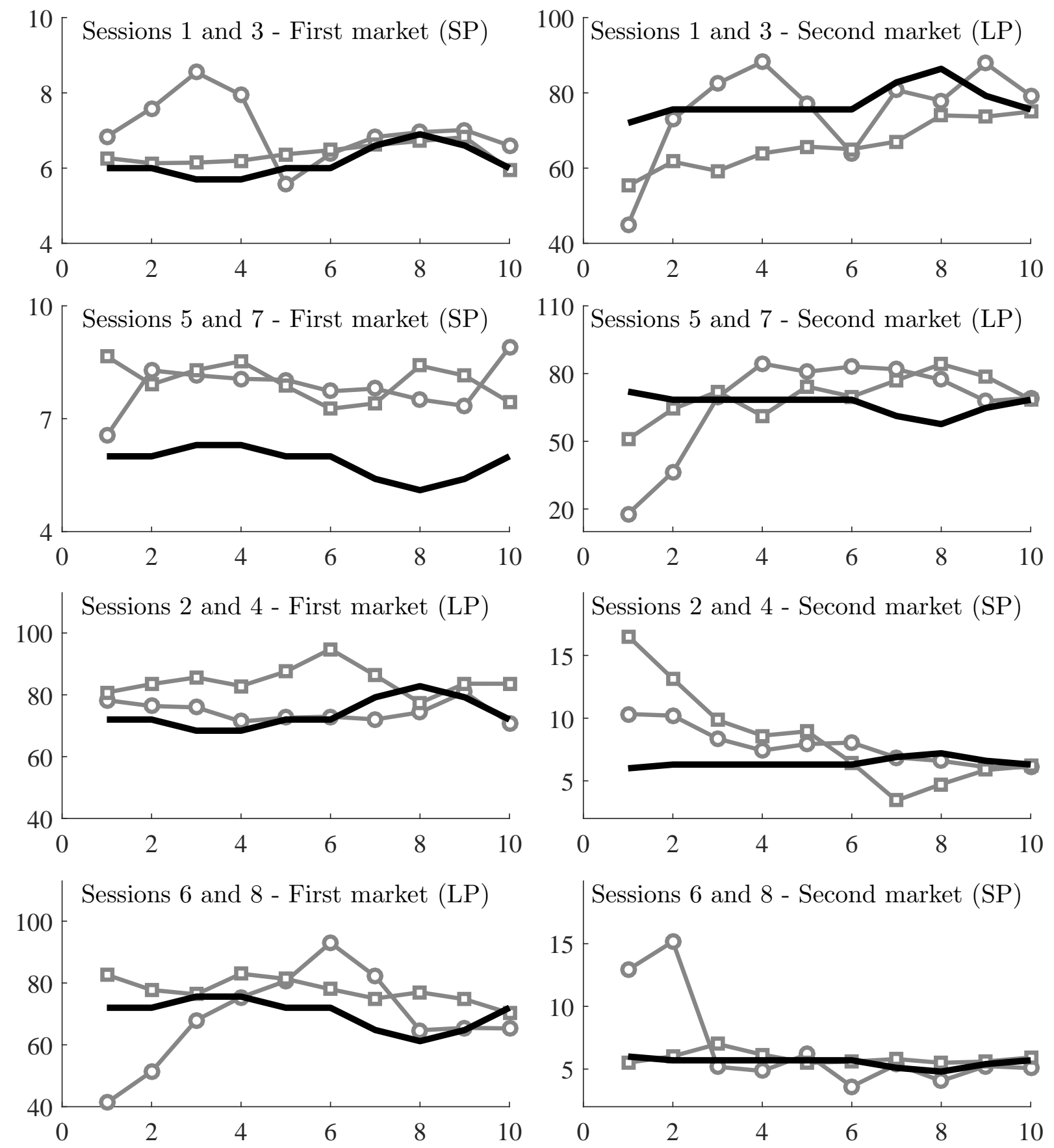

-FV $\rightarrow$ - Individual markets $\multimap-$ - Individual markets 


\section{Figure 2}

Distributions of $R A D_{p, t}$ and $R D_{p, t}$ for large price markets (solid black lines) and small price markets (dashed gray lines). Empirical cumulative distribution functions are represented for (1) the aggregate level; (2) first markets; and, (3) second markets. Reported p-values are associated with Mann-Whitney U tests between small price markets and large price markets.
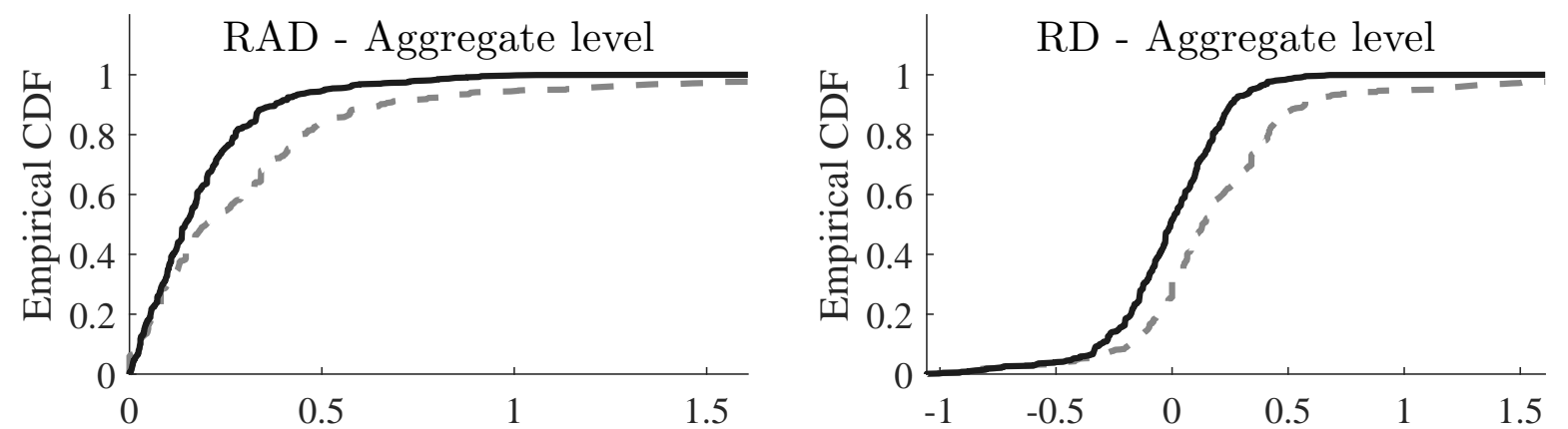

Mann-Whitney U test: p-value $<0.001$

Mann-Whitney U test: p-value $<0.001$
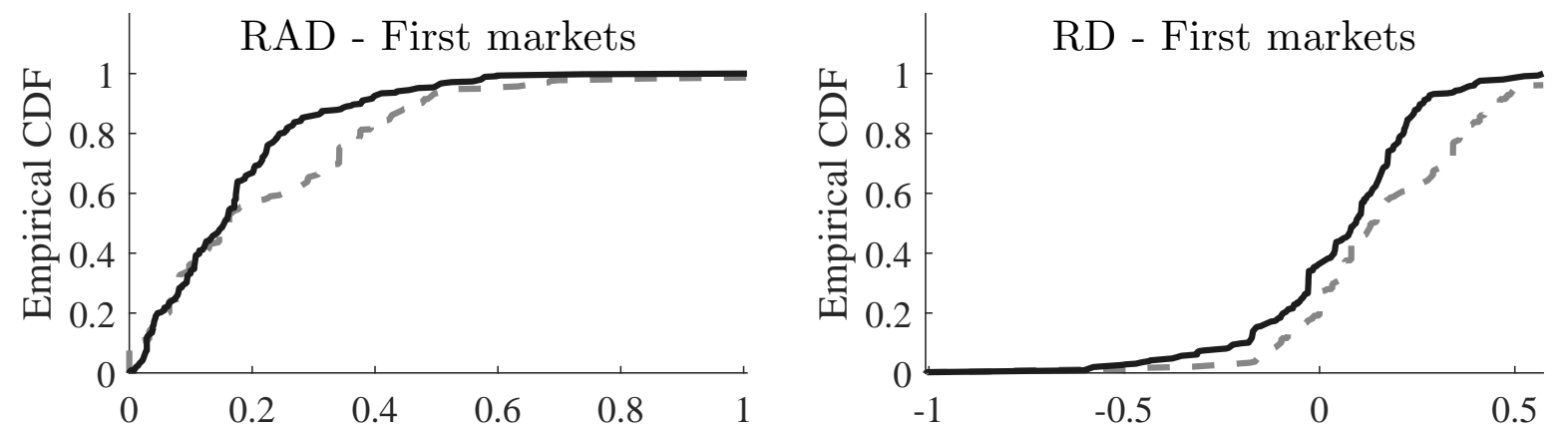

Mann-Whitney U test: p-value $<0.01$

Mann-Whitney U test: p-value $<0.001$
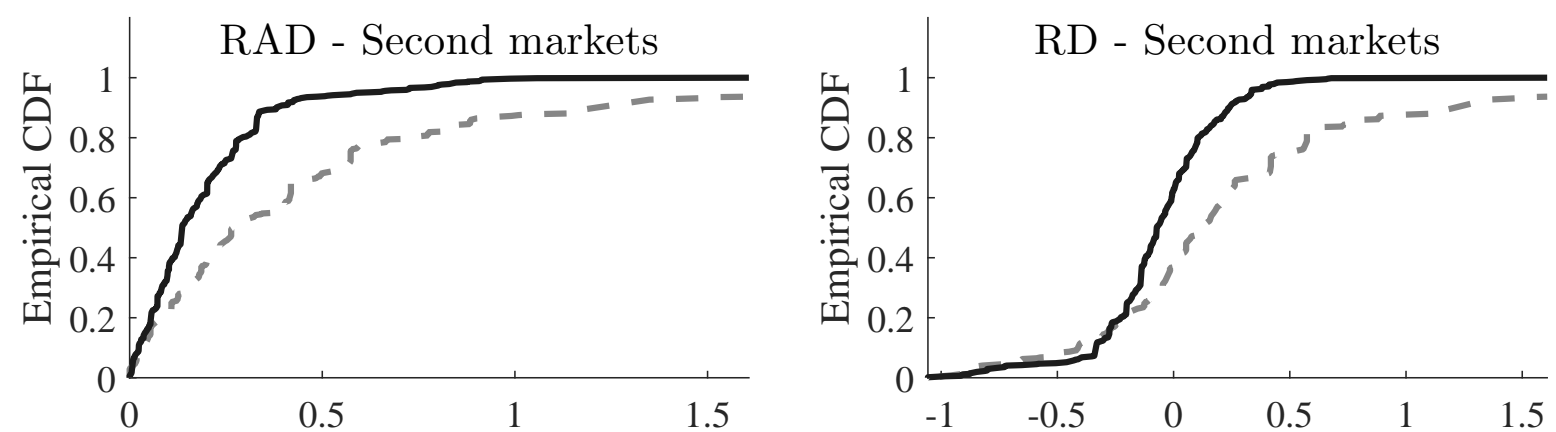

Mann-Whitney U test: p-value $<0.001 \quad$ Mann-Whitney U test: p-value $<0.001$

— Large price markets - - Small price markets 


\section{Table 1}

Panel A gives the basic sequences of cash-flows used in the experiment. The cash-flows realizations used in the experiment are randomly generated but determined in advance to ensure comparability. Sequences S3 and S4 are obtained by "mirroring" (at the unconditional expected value of 6) sequences S1 and S2. For large price markets, the sequences are scaled up by 12 . The first (second) line of Panel B gives the number of units of asset (cash) in the different portfolios. Portfolios P1 to P3 (P4 to P6) correspond to the small (large) price markets. Quantities are determined to have a theoretical portfolio value in large price markets equal to 12 times the theoretical portfolio value in small price markets.

\begin{tabular}{|c|c|c|c|c|c|c|c|c|c|c|}
\hline \multicolumn{11}{|c|}{ Panel A: Time series of cash-flows } \\
\hline Periods & 1 & 2 & 3 & 4 & 5 & 6 & 7 & 8 & 9 & 10 \\
\hline Basic sequence 1 (S1) & 0.6 & 0.3 & 0.6 & 0.9 & 0.6 & 1.2 & 0.9 & 0.3 & 0.0 & 0.6 \\
\hline Basic sequence 2 (S2) & 0.9 & 0.6 & 0.6 & 0.6 & 0.6 & 1.2 & 0.9 & 0.0 & 0.3 & 0.6 \\
\hline Mirrored sequence 1 (S3) & 0.6 & 0.9 & 0.6 & 0.3 & 0.6 & 0 & 0.3 & 0.9 & 1.2 & 0.6 \\
\hline Mirrored sequence $2(\mathrm{~S} 4)$ & 0.3 & 0.6 & 0.6 & 0.6 & 0.6 & 0 & 0.3 & 1.2 & 0.9 & 0.6 \\
\hline \multicolumn{11}{|c|}{ Panel B: Portfolio composition } \\
\hline & \multicolumn{5}{|c|}{ Small price market } & \multicolumn{5}{|c|}{ Large price market } \\
\hline Portfolios & & 1 & P2 & & P3 & & $\mathrm{P} 4$ & $\mathrm{P} 5$ & & $\mathrm{P} 6$ \\
\hline Units of asset & & 3 & 6 & & 9 & & 3 & 6 & & 9 \\
\hline $\begin{array}{l}\text { Amount of experimental } \\
\text { currency (ECU) }\end{array}$ & & 82 & 64 & & 46 & & 984 & 768 & & 552 \\
\hline
\end{tabular}

Table 2

Averages for RAD and RD. At the aggregate level, all markets are pooled together ( 8 sessions $\times 2$ markets). First markets (Second markets) correspond to the first (second) market of each session (8 markets). Small to large (Large to small) corresponds to the four sessions which starts by a small (large) price market.

\begin{tabular}{lcccc}
\hline & \multicolumn{2}{c}{ Relative absolute deviation (RAD) } & \multicolumn{2}{c}{ Relative deviation (RD) } \\
\cline { 2 - 5 } & Small price markets & Large price markets & Small price markets & Large price markets \\
\cline { 2 - 5 } Aggregate level & 0.3258 & 0.1875 & 0.2090 & -0.0144 \\
First markets & 0.2344 & 0.1750 & 0.1744 & 0.0535 \\
Second markets & 0.4935 & 0.1968 & 0.2725 & -0.0645 \\
Small to large & 0.2344 & 0.1968 & 0.1744 & -0.0645 \\
Large to small & 0.4935 & 0.1750 & 0.2725 & 0.0535 \\
\hline
\end{tabular}


Table 3

Within-participants: Paired observations for RAD and RD

\begin{tabular}{lcccccc}
\hline & \multicolumn{2}{c}{ All periods } & \multicolumn{2}{c}{ Without first period } & \multicolumn{2}{c}{ Without two first periods } \\
\cline { 2 - 7 } & RAD & RD & RAD & RD & RAD & RD \\
\cline { 2 - 7 } Small price markets & 0.3926 & 0.2671 & 0.3201 & 0.1919 & 0.2836 & 0.1422 \\
Large price markets & 0.2087 & -0.0078 & 0.1896 & 0.0321 & 0.1856 & 0.0513 \\
Difference & $0.1838^{* * *}$ & $0.2749^{* * *}$ & $0.1305^{* * *}$ & $0.1598^{* * *}$ & $0.0980^{* * *}$ & $0.0909^{* * *}$ \\
& $(5.1970)$ & $(6.7039)$ & $(5.3343)$ & $(5.3050)$ & $(5.1389)$ & $(3.7877)$ \\
\hline
\end{tabular}

This table presents the within-traders comparison between small price markets and large price markets. For each trader and each market, we compute the average of RAD (and RD). Statistical significance is assessed with a Wilcoxon signed-rank test. $z$-statistics are reported in parentheses. $* * * / * * / *$ correspond to $1 \% / 5 \% / 10 \%$ significance levels. 


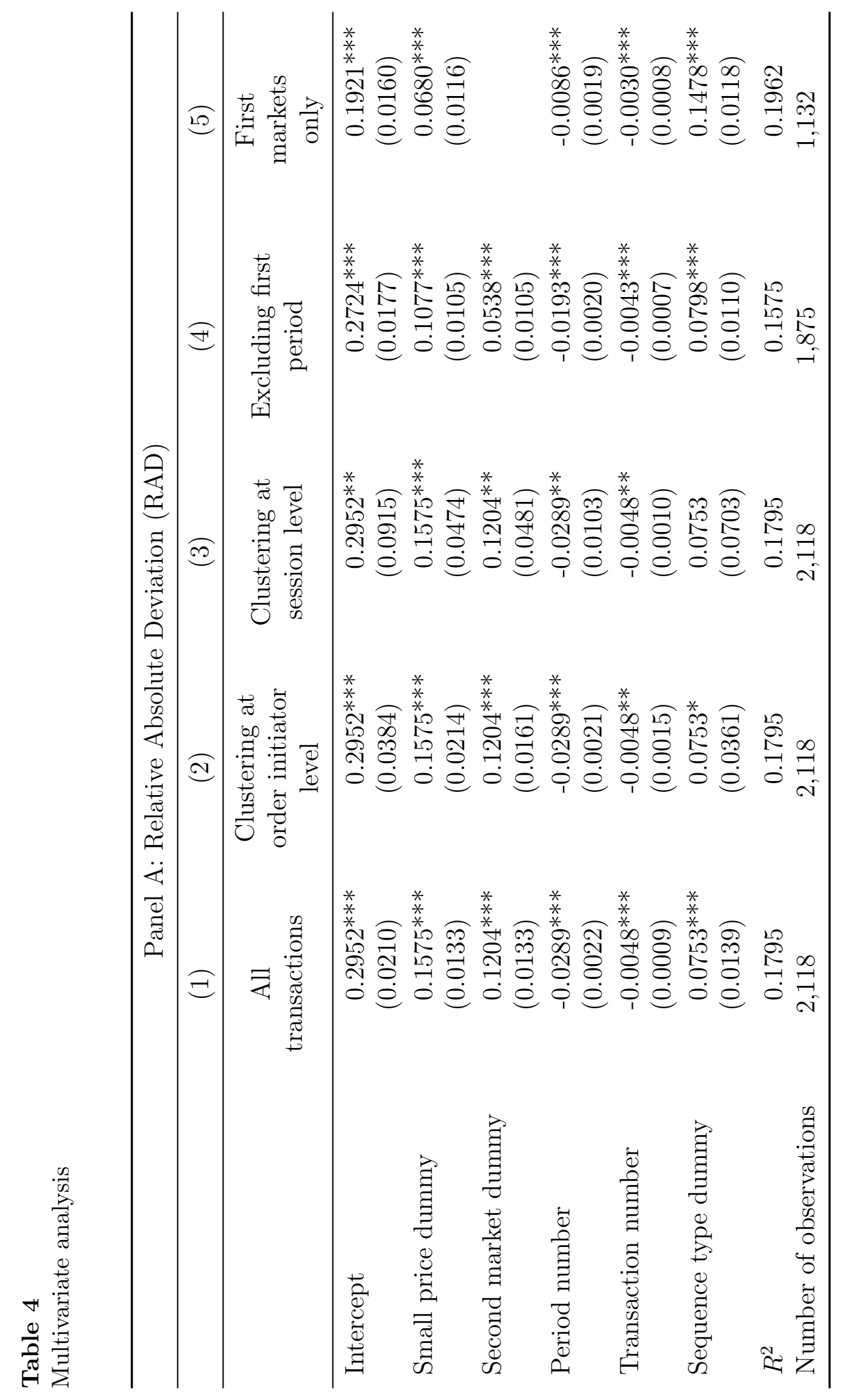




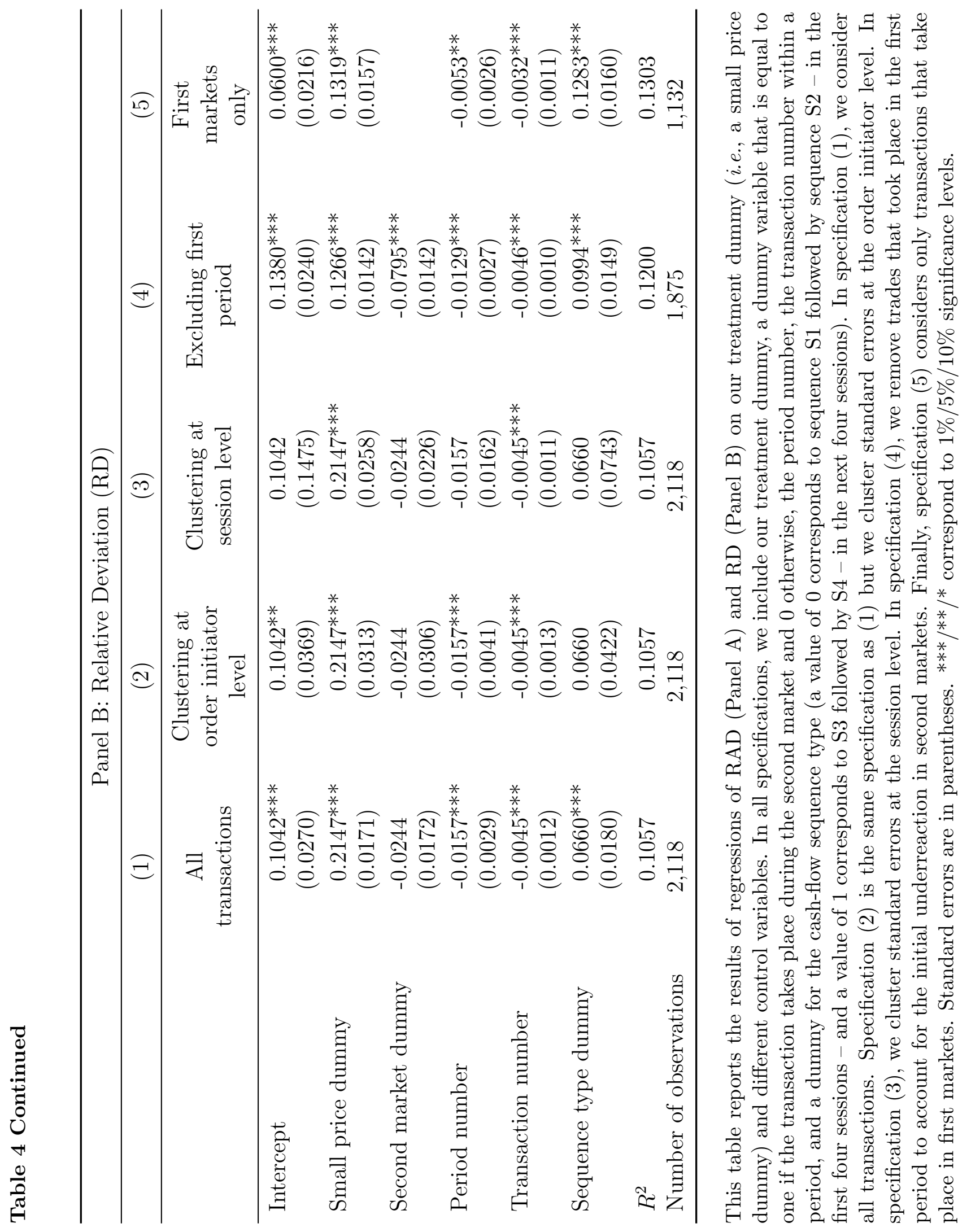


Table A1

Summary of the experiment

\begin{tabular}{lccccrrrrrr}
\hline & \multicolumn{2}{c}{ Type of market } & \multicolumn{2}{c}{ Cash-flow sequence } & \multicolumn{2}{c}{ Average FV } & \multicolumn{2}{c}{ Average RAD } & \multicolumn{2}{c}{ Average RD } \\
\hline & Market 1 & Market 2 & Market 1 & Market 2 & Market 1 & Market 2 & Market 1 & Market 2 & Market 1 & Market 2 \\
\hline Session 1 & Small price & Large price & S1 & S2 & 6.15 & 77.40 & 0.1661 & 0.1288 & 0.1425 & -0.0237 \\
Session 2 & Large price & Small price & S1 & S2 & 73.80 & 6.45 & 0.0743 & 0.2255 & 0.0103 & 0.2085 \\
Session 3 & Small price & Large price & S1 & S2 & 6.15 & 77.40 & 0.0505 & 0.1542 & 0.0358 & -0.1464 \\
Session 4 & Large price & Small price & S1 & S2 & 73.80 & 6.45 & 0.1510 & 0.5004 & 0.1461 & 0.2985 \\
Session 5 & Small price & Large price & S3 & S4 & 5.85 & 66.60 & 0.3395 & 0.2615 & 0.3395 & 0.0032 \\
Session 6 & Large price & Small price & S3 & S4 & 70.20 & 5.55 & 0.1952 & 0.4198 & -0.0209 & 0.2187 \\
Session 7 & Small price & Large price & S3 & S4 & 5.85 & 66.60 & 0.3661 & 0.1491 & 0.3661 & 0.0523 \\
Session 8 & Large price & Small price & S3 & S4 & 70.20 & 5.55 & 0.1105 & 0.0764 & 0.1055 & 0.0560 \\
\hline
\end{tabular}

Our experiments consists of 8 sessions. Each session contains one small price market and one large price market. Cash-flow sequences are determined in Table 1. 


\section{CEE-M Working Papers' 12018}

WP 2018 - 01: $\quad$ Ilaria Brunetti, Mabbel Tidball, \& Denis Couvet « Relationship Between Biodiversity and Agricultural Production »

WP 2018 - 02: $\quad$ Phillippe Le Coent, Raphaële Préget \& Sophie Thoyer « Do farmers follow the herd? The influence of social norms in the participation to agri-environmental schemes »

WP 2018 - 03: $\quad$ Ludivine Roussey \& Raphaël Soubeyran

« Overburdened judges »

WP 2018 - 04: $\quad$ Nicolas Quérou

«Interacting collective action problems in the Commons »

WP 2018 - 05: $\quad$ Karine Constant \& Marion Davin

«Unequal vulnerability to climate change and the transmission of adverse effects through international trade »

WP 2018 - 06: $\quad$ Henrik Andersson \& Emmanuelle Lavaine

« Nitrates and property values: evidence from a french market intervention »

WP 2018 - 07: $\quad$ Mamadou Gueye, Nicolas Querou \& Raphaël Soubeyran

«Does equity induce inefficiency? An experiment on coordination »

WP 2018 - 08: $\quad$ Douadia Bougherara \& Laurent Piet

« On the role of probability weighting on WTP for crop insurance with and without yield skewness»

WP 2018 - 09: $\quad$ Douadia Bougherara, Carole Ropars-Collet \& Jude Saint-Gilles « Impact of private labels and information campaigns on organic and fair trade food demand»

WP 2018 - 10: $\quad$ Sylvain Chabé-Ferret, Philippe Le Coent, Arnaud Reynaud, Julie Subervie $\&$ Daniel Lepercq

« Can we nudge farmers Into saving water? Evidence from a randomized experiment »

WP 2018 - 11: $\quad$ Dimitri Dubois, Stefano Farolfi, Phu Nguyen-Van \& Juliette Rouchier "Information sharing is not always the right option when it comes to CPR extraction management: experimental finding »

WP 2018 - 12: $\quad$ Tristan Le Cotty, Elodie Maitre d'Hotel, Raphaël Soubeyran \& Julie Subervie «Inventory credit as a commitment device to save grain until the hunger season »

1 CEE-M Working Papers

Contact : laurent.garnier@inra.fr/ 0499613121 
WP $2018-13:$

Brice Magdalou

«An abstract model of welfare-improving transfers »

WP 2018 - 14: $\quad$ Mickael Beaud, Mathieu Lefebvre $\&$ Julie Rosaz

« Other-regarding preferences and giving decision in risky environments: experimental evidence »

WP 2018 - 15: $\quad$ Kate Farrow, Lisette Ibanez \& Gilles Grolleau

«Designing more effective norm interventions: the role of valence »

WP 2018 - $16 \quad$ Yu-Jui Huang, Adrien Nguyen-Huu \& Xun Yu Zhou

«General stopping behaviors of naïve and non-committed sophisticated agents, with application to probability distortion »

WP 2018 - 17 Sophie Clot, Gilles Grolleau, Lisette Ibanez

«What did you do before? Moral (in)consistency in pro-environmental choice »

WP 2018 - 18 Sébastien Duchêne, Eric Guerci, Nobuyuki Hanaki \& Charles N. Noussair " The effect of short selling and borrowing on market prices and traders' behavior »

WP 2018 - 19 Philippe Delacote, Gwenolé Le Velly \& Gabriela Simonet

"The effect of short selling and borrowing on market prices and traders' behavior»

WP 2018 - $20 \quad$ Luc Behaghel, Karen Macours \& Julie Subervie

«Can RCTs help improve the design of CAP? »

WP 2018 - $21 \quad$ Tristan Roger, Wael Bousselmi, Patrick Roger \& Marc Willinger

«Another law of small numbers: Patterns of trading prices in experimental markets » 